\title{
Switching immunoglobulin products, what are the implications? Result of 2018 census of immunology centres
}

\author{
Authors: Claire Bethune ${ }^{A}$ and Richard Herriot ${ }^{B}$
}

The use of regular infusions of immunoglobulin is well established as a treatment for patients with antibody deficiency and for patients requiring immunomodulation. Although efficacy is believed to be equivalent for the different immunoglobulin products, it is generally regarded as best practice not to switch from one product to another unless there is a clinical reason to change. Changes in commissioning guidance and issues with the supply of some immunoglobulin products to the UK resulted in a requirement for a significant number of patients to switch between immunoglobulin products in 2017-2018. Data from the 2018 UK Primary Immunodeficiency census has been used to evaluate the clinical results of switching. Results from 30 immunology centres reported a total of 802 immunoglobulin product switches. Twelve reactions were recorded, none of which required admission to hospital, one patient was treated with oral corticosteroids, the others required either no treatment or treatment with oral antihistamines. This review of immunoglobulin product switch reactions gives a clearer indication regarding the safety of product switching than has previously been published.

KEYWORDS: Immunoglobulin, immunodeficiency, immunomodulation

\section{Background}

The use of regular infusions of immunoglobulin (intravenous (IV) or subcutaneous (SC)) to treat patients with antibody deficiency is well established as a treatment for patients with primary and secondary immunodeficiency. Immunoglobulin is also used for immunomodulation in specific conditions. Although efficacy is believed to be equivalent for the different immunoglobulin products, it is generally regarded as best practice not to switch from one product to another unless there is a clinical reason to change (primarily to avoid adverse

Authors: ${ }^{\text {A }}$ consultant immunologist, University Hospital Plymouth NHS Trust, Plymouth, UK; ${ }^{B}$ consultant immunologist, Aberdeen Royal Infirmary, Aberdeen, UK reactions but also, potentially, to reduce batch-associated infection risk and complicating any process of post-infusion infection tracking). ${ }^{1}$ Manufacture of immunoglobulin products varies and the products are not identical, particularly in respect of excipient components; as a result there is an established perception of potential risk of unpredictable reactions linked to non-clinically driven product switches in individual patients. ${ }^{2,3}$ Traceability has been cited as another reason not to switch immunoglobulin products. ${ }^{1}$ In the past it is has been more challenging to trace patients who have received a particular product if they have switched between a number of products, however improved electronic recording of products reduces this difficulty. ${ }^{4}$ It has also been assumed that the potential risk of infection transmission from immunoglobulin would increase if a change in manufacturer/product led to a change in the plasma donor pool. ${ }^{2}$ However this assertion does centrally rely on a supposition that any particular immunoglobulin manufacturer has a plasma donor pool which is stable over a protracted period of time, to date there has been no evidence to support this assertion.

A combination of changes in commissioning arrangements in England and issues relating to the supply and/or the unit cost of some specific immunoglobulin products has led to logisticallydriven switching of immunoglobulin brand products being undertaken in many centres in the UK since July 2017. A census carried out in May 2018 by the UK Primary Immunodeficiency Network (UKPIN) utilising the Royal College of Physicians (RCP)hosted Quality in Primary Immunodeficiency Services (QPIDS) accreditation platform included questions designed to explore the number of patients affected by the switching of immunoglobulin products, the frequency of reactions to new products and the effects of switching on the immunodeficiency clinical service providers themselves. $^{5}$

\section{Methods}

Questions regarding immunoglobulin switching were included in the annual UKPIN/QPIDS census of immunodeficiency centres. The census survey was distributed electronically by the RCP accreditation unit to the clinical service lead for all immunodeficiency centres registered with the QPIDS accreditation scheme. Two services not registered with the scheme were contacted directly and one of these non-registered services also completed the census. 
The following questions were included in the census electronic questionnaire.

> How many primary immunodeficiency (PID) / secondary immunodeficiency (SID) patients on immunoglobulin replacement prescribed through your service have switched products as a result of 2017 commissioning guidance?

> How many PID/SID patients managed by your service have been switched as a result of immunoglobulin product withdrawal in the last 12 months?

$>$ How many patients have suffered a local reaction following product switch?

$>$ How many patients have suffered a systemic reaction following product switch?

$>$ How many PID/SID patients have had treatment delayed due to product non-availability?

Centres were also asked to provide details regarding the arrangements made for product switch including:

> number of patients attended for previously planned appointments

$>$ annual hospital review bought forward

$>$ additional appointment specifically for switch

was other nursing activity displaced as a result of switch appointments and/or were additional hours worked?

Centres reporting reactions following product switch were contacted directly and details of the reactions were clarified. Specifically further questions were asked regarding the nature of the reaction, the requirement for hospitalisation, treatment administered and outcome.

\section{Results}

Retrospective census data was collected from 33/36 (92\%) UK immunodeficiency centres. ${ }^{5}$ Thirty out of thirty-three centres reported that immunoglobulin product switches had occurred in their centres between July 2017 and May 2018. The data were analysed to define the number of product switches which had taken place, adverse reactions which had taken place in association with product switches and impact of switches on service providers.

\section{Number of product switches}

A total of 802 immunoglobulin product switches were reported. Most of the 802 product switches in immunodeficiency centres were undertaken as a result of product withdrawal or shortage (79\%), a smaller number of patients were switched as a result of NHS England commissioning guidance SSC1760, 07 July 2017 (21\%; supplementary material S1). The shortage of immunoglobulin products has had an impact on the timing of infusions with over half of the services (17/33) reporting that some patients had infusions delayed due to products not being available.

\section{Reactions following product switch}

A total of five local reactions were reported from 32 centres who answered this question (in one case the number of local reactions was reported as 'unknown'; Table 1).

A total of seven systemic reactions were reported from 33 centres who answered this question, details in Table 2 . All of the four patients who were described as having systemic reactions following switch from one SC product to another were managed as outpatients and all four were reported to subsequently tolerate an alternative SC immunoglobulin product. All three of the patients described as having systemic reactions after switching from an IV to a different IV product had received their infusions in hospital, two of these patients described subsequent symptoms at home but did not seek treatment. One of the patients who had a reaction after IV switch was seen in the emergency department due to back pain after the new product was given and outpatient management with analgesia was prescribed.

\section{Resource implication of switching immunoglobulin products}

Twenty-two services reported that additional appointments were required to organise immunoglobulin switches (producing 300 additional appointments nationally). In 17 services, product switch was arranged to coincide with previously planned infusions, and in five services the immunoglobulin product switch was arranged by bringing the annual review appointment forward.

Twenty-four services reported that the requirement to switch products led to other nursing activity being displaced. These activities included outpatient clinics, home therapy training techniques for new patients, nursing support for hospital-based infusions, administrative work and continuing professional development (CPD). In order to accommodate the requirement for increased nursing input, nursing overtime was worked in 10 services.
Table 1. Local reactions following product switch

$\begin{array}{ll}\text { Description of the local reaction } & \begin{array}{l}\text { Was the patien } \\ \text { hospitalised for } \\ \text { treatment? }\end{array} \\ \text { Redness and mild itch (resolved in hours) } & \text { No } \\ \text { Redness and mild itch (resolved in hours) } & \text { No } \\ \text { Redness and mild itch (resolved in hours) } & \text { No } \\ \text { Red rash on legs } & \text { No } \\ \text { Local pruritus } & \text { No }\end{array}$

\begin{tabular}{|c|c|}
\hline $\begin{array}{l}\text { Was treatment } \\
\text { given as an } \\
\text { outpatient? }\end{array}$ & Outcome \\
\hline Chlorpheniramine & Continued product, mild symptoms ongoing \\
\hline Chlorpheniramine & Continued product, mild symptoms ongoing \\
\hline Chlorpheniramine & Continued product, mild symptoms ongoing \\
\hline Antihistamines & Continued product, no further symptoms \\
\hline Antihistamines & $\begin{array}{l}\text { Continued new product for } 4 \text { months before } \\
\text { reverting back to original product }\end{array}$ \\
\hline
\end{tabular}


Table 2. Systemic reactions to product switch

\begin{tabular}{|c|c|c|c|c|}
\hline $\begin{array}{l}\text { SC or IV } \\
\text { administration } \\
\text { switch }\end{array}$ & Description of the systemic reaction & $\begin{array}{l}\text { Was the patient } \\
\text { admitted to hospital? }\end{array}$ & $\begin{array}{l}\text { Was treatment } \\
\text { given as an } \\
\text { outpatient? }\end{array}$ & Outcome \\
\hline SC-SC & $\begin{array}{l}\text { Joint and neck pain, headache and stomach } \\
\text { ache after infusions (lasting 1-24 hours) }\end{array}$ & No & No & $\begin{array}{l}\text { Switched to alternative } \\
\text { product, no further } \\
\text { symptoms }\end{array}$ \\
\hline SC-SC & $\begin{array}{l}\text { Subjective 'swimming in head' dizzy and } \\
\text { fatigue after infusions (lasting up to } 7 \text { days } \\
\text { after infusions). No objective symptom on } \\
\text { observed infusion but patient described } \\
\text { symptoms as being reproducible }\end{array}$ & No & No & $\begin{array}{l}\text { Switched to alternative } \\
\text { product, no further } \\
\text { symptoms }\end{array}$ \\
\hline SC-SC & $\begin{array}{l}\text { Headache, malaise, abdominal pain. Painful } \\
\text { skin rash }\end{array}$ & No & $\begin{array}{l}\text { Paracetamol, } \\
\text { antihistamines, } \\
\text { prednisolone } \\
\text { ( } 3 \text { days) }\end{array}$ & $\begin{array}{l}\text { Switched back to } \\
\text { previous product }\end{array}$ \\
\hline SC-SC & $\begin{array}{l}\text { Palpitations during infusion. Subsequent } \\
\text { ( } 2 \text { weeks later) widespread raised rash }\end{array}$ & No & Cetirizine & $\begin{array}{l}\text { Switched to alternative } \\
\text { and rash resolved }\end{array}$ \\
\hline IV-IV & $\begin{array}{l}\text { Fever, headache, flu-like illness self- } \\
\text { described shaking: commenced evening of } \\
\text { infusion lasted } 1-2 \text { days }\end{array}$ & No & No & $\begin{array}{l}\text { Switched to alternative } \\
\text { IV product }\end{array}$ \\
\hline \multirow[t]{3}{*}{ IV-IV } & $\begin{array}{l}\text { Onset of severe back pain } 1 \text { hour after } \\
\text { leaving clinic. }\end{array}$ & No & Analgesia & $\begin{array}{l}\text { Switched to alternative } \\
\text { IV product }\end{array}$ \\
\hline & $\begin{array}{l}\text { Attended emergency department, treated } \\
\text { with pain relief and discharged. }\end{array}$ & & & \\
\hline & $\begin{array}{l}\text { Fatigue and on-going back pain continued } \\
\text { for 'a couple of days' }\end{array}$ & & & \\
\hline \multirow[t]{2}{*}{ IV-IV } & $\begin{array}{l}\text { Long standing history of intolerances of a } \\
\text { number of products. }\end{array}$ & No & No & $\begin{array}{l}\text { Switched back to } \\
\text { original product }\end{array}$ \\
\hline & $\begin{array}{l}\text { Patient reported tiredness on the day after } \\
\text { the infusion with joint and muscle pains }\end{array}$ & & & \\
\hline
\end{tabular}

\section{Discussion}

Changing from one immunoglobulin product to another has a resource implication for hospital service providers and inconveniences patients. The majority of patients receiving SC immunoglobulin self-administer their treatment at home. In view of the potential for patients to have reactions to a new immunoglobulin product, it is standard practice that when a new immunoglobulin product is started, patients normally infusing at home would have an observed infusion in hospital. Unless planned appointments for observed infusions were already booked when the switch was needed, a product switch required either an additional hospital visit or an appointment to be bought forward. This is inconvenient for patients and has an impact on service provision. All services where product switches were undertaken reported that other nursing activity was displaced (including clinics, other outpatient and day case work, CPD and administration) and in 10 services nurses worked overtime in order to facilitate the switch.

This work is limited as it relied on retrospective recollection by the immunology teams regarding the number of reactions experienced by their patients. However, product switch is not routine practice and patients will have been in close communication with centres at the time of the switch, with the requirement for new prescriptions and observed infusions of the new product. It would therefore be likely that nursing teams would have been aware of any reactions.

A total of 12 reactions to the switched product were reported. Local reactions to SC immunoglobulin are not unusual and there were some reports that switching to a new product resulted in an improvement of mild local reactions experienced with a previous product. Data regarding improvement of symptoms following switching were not collected in this census.

None of the reactions reported in this retrospective census led to inpatient management following a product switch.

The information arising from this review is out of step with established thinking and clinician/patient experience as regards adverse reactions linked to product changes in the context of primary immunodeficiency. It suggests that there may be more flexibility regarding arrangements for product switching than previously thought particularly with regard to SC-SC product switches. Notwithstanding the logistical challenges and concerns regarding possible adverse reactions, these data provide evidence that product switches are feasible in patients with primary immunodeficiency. Given the volatility of immunoglobulin supplies for the foreseeable future, this study provides useful data to inform any future round of switching, should this prove to be necessary. 


\section{Supplementary material}

Additional supplementary material may be found in the online version of this article at www.clinmed.rcpjournal.org:

S1 - National framework agreement for human immunoglobulins.

\section{References}

1 Misbah SA. Should therapeutic immunoglobulin be considered a generic product? An evidence-based approach. J Allergy Clin Immunol Pract 2013;567-72.

2 Ameratunga R, Sinclair J, Kolbe J. Increased risk of adverse events when changing immunoglobulin preparations. Clin Exp Immunol 2004;136:111-3.
3 Aghamohammadi A, Farhoudi A, Nikzad M et al. Adverse reactions of prophylactic intravenous immunoglobulin infusions in Iranian patients with primary immunodeficiency. Ann Allergy Asthma Immunol 2004;92:60-4.

4 Chapel HM. Safety and availability of immunoglobulin replacement therapy in relation to potentially transmissable agents. Clin Exp Immunol 1999;118(Suppl 1):22-34.

5 Royal College of Physicians. Quality in Primary Immunodeficiency Services. www.qpids.org.uk.

Address for correspondence: Dr Claire Bethune, University Hospital Plymouth NHS Trust, Peninsula Specialist Immunology and Allergy Service, Derriford Road, Plymouth PL6 8DH, UK. Email: claire.bethune@nhs.net

\section{Supervising quality improvement projects} A guide for supervisors

This online resource has been developed by the Royal College of Physicians (RCP) to help clinicians from any specialty to identify learning opportunities relating to quality improvement, to support and guide their trainees throughout their quality improvement projects.

For more information, please email: elearning@rcplondon.ac.uk

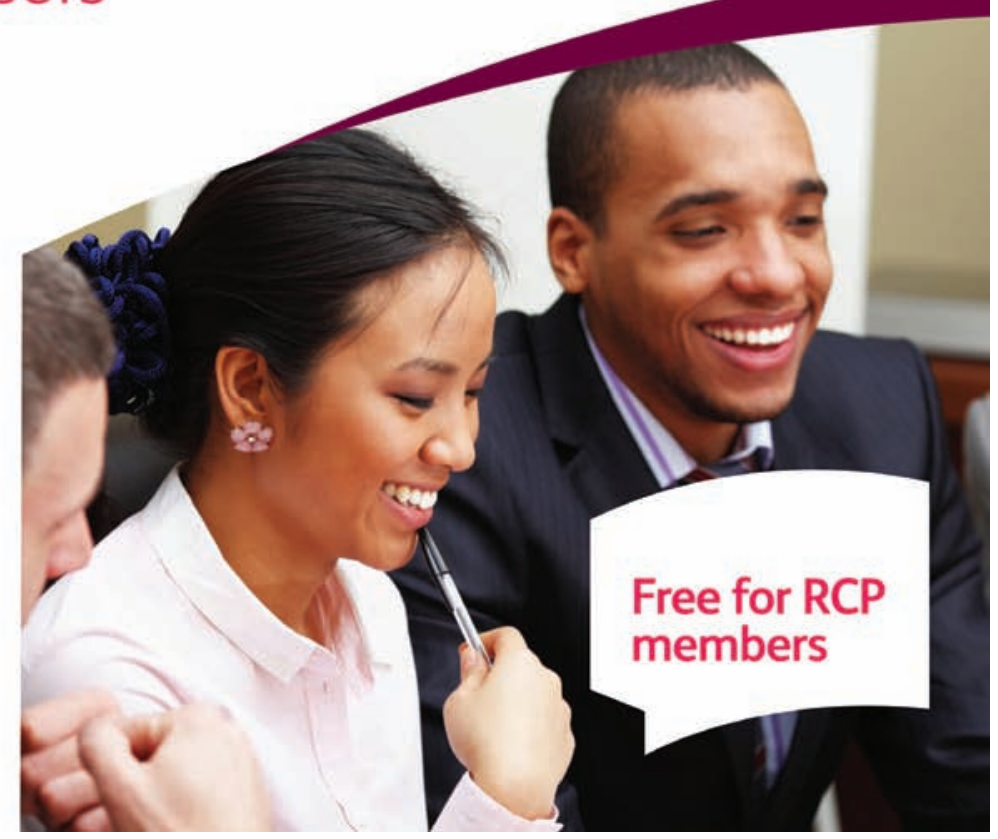

